doi: $10.21500 / 22563202.3993$

\title{
Lo publico en la antigüedad, un retorno al ágora
}

\author{
Juan Fernando Aguilar ${ }^{1}$ \\ Universidad de San Buenaventura
}

Referencia norma APA: Aguilar, J. F. (Ed.). (2018). Lo publico en la antigüedad, un retorno al ágora. Rev. Guillermo de Ockham, 16(2), In press. doi: $10.21500 / 22563202.3993$

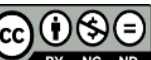

This work is licensed under CCBY-NC-ND

Hace 50 años, cuando se forjaba la era de los discursos revolucionarios, intelectuales y estudiantes se tomaron las calles de París para protestar contra la injusticia y la desigualdad que aún anidaba, no solo en Francia, sino en toda Europa. La historia recordaría aquella época de marchas y huelgas como Mayo del 68, el momento en que la política se hizo en la calle, en que la juventud decidió no callar más y en el que pensadores como Jean-Paul Sartre y Michel Foucault abandonaron las aulas universitarias para debatir en las calles, en las plazas públicas, en medio del sudor, la represión estatal y los gritos libertarios que convocarían nuevos movimientos alrededor del mundo.

El Mayo Francés, más allá de ser una revolución, fue un retorno al pensamiento griego, a lo público, tal como lo declararía François Gagin, a la política y la oratoria que se celebraban y confrontaban en el ágora, la plaza pública donde se igualaban los poderes tras el decaimiento de la monarquía micénica a partir del Siglo VIII A.C. y el surgimiento de las polis donde, para aspirar a la política, debía debatirse frente al pueblo, frente a una Atenas que se haría juez de cualquier discurso que pretendiera dirigirla, que se haría partícipe de todo saber que buscase la verdad, la misma que debería yacer bajo la mirada pública, ya no reservada a los reyes o a los aristócratas (Gagin, 2011). Mayo del 68 significó un vehemente regreso a las plazas públicas, al igual que las posteriores protestas y teorías libertarias que seguirían repitiéndose a lo largo del siglo XX y XXI, llegando también hasta América Latina, envuelta en sus propias luchas.

\footnotetext{
${ }^{1}$ Psicólogo, Facultad de psicología Universidad de San Buenaventura. E-Mail: serpico096@gmail.com
} 
Hoy, medio siglo después de las marchas que sacudieron a París y al mundo, el pensador francés, François Gagin, heredero del pensamiento de Mayo del 68, propuso en diciembre del 2018 un breve pero impetuoso retorno al ágora al salir de la Universidad del Valle para dictar una clase en La Plaza de Caicedo de Cali. Ello consistía en una cátedra destinada a dignificarse en mitad de la calle, en medio de la mirada atenta de los estudiantes que escuchaban el tema titulado: "Lo público en la Antigua Grecia", donde Gagin, haciendo uso de la apertura de la plaza, ofició el papel del filósofo que transmite su conocimiento, aún si el mismo resulte contrario a las ideas imperantes de la polis, tal como el mismo Gagin lo resalta al declarar que la ciudad resulta insuficiente para el filósofo, también peligrosa, como lo demuestra el destino capital de Sócrates. Lo público se erige entonces como lo demostrado y debatido en el ágora, como una oportunidad colectiva para la libertad singular, allí donde se decidirá la política o se cuestionarán las verdades que alguna vez se creyeron inamovibles, allí donde el pensador y debatiente ha debido fortalecerse en lo privado antes de enfrentar su discurso al de sus adversarios y espectadores, antes de ingresar a la esfera de lo público.

Lo privado, en relación a lo público, hace referencia al reconocimiento griego y posteriormente romano, de que para resistir el fragor político de las polis, o los cuestionamientos de saberes, era menester formarse en privado, en el ideal griego del tekhne tou biou, el arte de vivir, la técnica de la existencia tal como la retomaría Foucault, o la Ciudadela Interior como la propondrían los estoicos como el emperador Marco Aurelio. Para Michel Foucault, desde el pensamiento griego, el gobierno de sí es necesario para el gobierno de los otros de la misma manera en que lo estudia Gagin al declarar en su cátedra que la contingencia privada debe satisfacerse en una primera instancia para llegar con plenitud a lo público. Sin embargo, tal como lo manifestarían los estudiantes del Mayo Francés, eventualmente la esfera privada sería invadida y conquistada por lo que Foucault llamaría la Biopolítica, el poder, ligado en buena medida al capitalismo, capaz de dictar no solo un estilo de vida, sino un cómo vivir (Vignale, 2013). Es aquí donde vuelve a ser preciso el arte de vivir griego, la técnica para ser más libre, para resistir las estructuras de dominancia de las polis y tener acceso a una relación política con la verdad, la misma que ha de buscarse a través del debate en el ágora, una relación que trascienda los absolutos y opte por ser siempre cuestionable.

Es en este cuestionamiento donde ocurrirá la tesis y la antítesis hegeliana, la reafirmación de sí mismo a través de la propia negación (Caligaris y Starosta, 2015); acaso, el proceso 
privado, interno, que los revolucionarios llevan a cabo cuando lo privado se ve invadido por el poder institucional y lo público, a la manera griega, aparece como el único espacio para la libertad individual. El revolucionario, o bien, todo aquel que pretenda cualquier libertad, deberá forjar entonces una relación y un deseo de verdad, renunciando y negando el Ser que era, para ser otro, renacido desde la intención política y dispuesto a la palabra, ya no privada, sino pública, ansiosa de escucharse, debatir y ser debatida. De forma ulterior, también ocurre, ya no en la negación del sí mismo, sino en su afirmación, la recursión de la palabra, del enunciado que se construye y se auto referencia (Mota, 2015); en este caso, en un ambiente político, e incluso idealizado bajo las formas de la estética griega cuando en el ágora, se enuncia y se jerarquiza el "Yo soy, yo quiero, yo propongo", que se manifiesta en la intención de libertad de una política griega, en el logos ideal de Sócrates donde cada ciudadano tiene derecho a la palabra.

Gagin argumenta en su clase al aire libre que Sócrates temía que el ágora se redujese a intereses políticos individuales, y ya no a una política con un telos, con un fin preciso y alcanzado a través del enfrentamiento de ideas. Sócrates, al denunciar que lo público se hallaba comprometido por el poder aristocrático que dictaba el destino y el arte de vivir atenienses, se propuso entrar a los espacios privados, como se narra en El Banquete, para hacerlos públicos a través de la filosofía y la oratoria. En muchos modos, es lo que ha logrado Gagin al salir de la universidad y tomarse una plaza central para hacerla un espacio de conocimiento e ideas, para hacerla un ágora aun sí su pensamiento, tal como acusaron a Sócrates, pueda ser tildado de corruptor por los poderes que rigen las polis, o por la demagogia discursiva tan despreciada por Aristóteles en el que se pretende una verdad a través de retóricas falaces, de una falsa libertad construida en lo público pero a través de intereses particulares.

Ahora bien, la libertad que otorga lo público se ha gestado en buena medida a través de lo que Aristóteles llamaría la Politeia, lo concerniente al estado, como lo podría ser una constitución política. La Politeia, en relación a las leyes atenienses, estaba destinada no solo a un orden, sino a la estética griega del saber de vivir y del cuidado de la polis para asegurar que los ciudadanos fuesen libres. Sin embargo, tal como lo sospecharon Sócrates, Aristóteles y Platón, los cínicos también consideraron que las leyes de Atenas podían ser contrarias e insuficientes para el filósofo, cuyo pensamiento no siempre iba acorde con la política ateniense en tanto que las leyes y el tekhne tou biou, al igual que los discursos del ágora, no son tampoco verdades incuestionables, ni deberían hacer eco 
a lo que Kant llamó durante la Ilustración el Imperativo Categórico, la Ley universal que pretende ser válida para todos los hombres, incluso si el mismo Kant propone a su vez que si bien el deber que proviene de la razón es necesario, el sufrimiento moral ante la duda de sí se debe cumplir o no, es síntoma de que se es libre (Crelier, 2011). Los cínicos promovieron un retorno a una sola ley: La natural. Provocaron, desde la ironía socrática convertida en sarcasmo y desafío, el retorno del filósofo a la polis, a la publicidad de las ideas y la denuncia de valores arbitrarios. En síntesis, como puntualiza Gagin, los cínicos propusieron un proyecto, una contracultura, acaso similar a la de Mayo del 68, y a todas las demás revoluciones culturales que la sucedieron.

En varias formas, lo que ha propuesto François Gagin reviste no solo un retorno al ágora, sino a su vez una contracultura al erigir la plaza como un espacio de pensamiento y debate al que todo ciudadano está invitado (Gagin, 2014); incluso sí, como lo demostraron los griegos con la ejecución de Sócrates, la filosofía no es del todo pública y a través de los siglos ha sido relegada a las academias, de donde no suele salir. Mas, Gagin, en medio de una plaza municipal hablando a través de un megáfono ante estudiantes y transeúntes que se acercan a escucharlo y a participar, ha sentado el precedente de que la filosofía y el pensamiento pueden darse en las calles, en el retorno al ágora, piedra fundante de Atenas. El filósofo, como lo pensaba Platón, tendrá dos caminos cuando la polis le resulte insuficiente: exiliarse en soledad, o con amigos, para gestar una sabiduría privada, o pretender cambiar la polis a través del incesante debate, del pensamiento que ha de ser y de mantenerse público. François Gagin ha escogido el segundo camino.

\section{Referencias}

Caligaris, G. y Starosta, G. (2015). La crítica marxiana de la dialéctica hegeliana. De la reproducción ideal a un proceso ideal a producción ideal de un proceso real, Revista Praxis Filosófica, 41, 81-112.

Crelier, A. (2011). La reflexión moral kantiana y el problema de conflicto de deberes, Revista Praxis Filosófica, 33, 11-31.

Gagin, F. (2014). ¿Es la contra-cultura cínica una negación de las Bellas Artes? Una provocación moderna cara al filósofo-artista. Eidos, 20, 247-270.

Gagin, F. (2011). Lo público y lo privado en los filósofos griegos. La cuestión de la libertad, Revista Praxis Filosófica, 15, 97-110.

Mota, S. (2015). Sobre el concepto de recursión y sus usos, Revista Praxis Filosófica, 40, 153-181. 
Vignale, S. (2013). Políticas de la vida y estética de la existencia en Michel Foucault, Revista Praxis Filosófica, 37, 169-192. 